\title{
ANALISIS FAKTOR-FAKTOR YANG MEMPENGARUHI ADOPSI CLOUD COMPUTING DI RUMAH SAKIT MUHAMMADIYAH
}

\author{
Moh. Bhanu Setyawan \\ Fakultas Teknik, Program Studi Tenik Informatika \\ Universitas Muhammadiyah Ponorogo \\ Email: mohammad.setyawan@gmail.com
}

\begin{abstract}
ABSTRAK
Artikel ini bertujuan untuk mengetahui faktor-faktor yang mempengaruhi adopsi cloud computing di rumah sakit Muhammadiyah di Indonesia dengan menggunakan Technology Acceptance Model (TAM). Sampel yang digunakan dalam penelitian ini adalah 51 sampel. Alat analisis yang digunakan Partial Least Square (PLS) pada program SmartPLS versi 2.0. Faktor pendukung dalam adopsi cloud computing : perceived ease of use, perceived usefulness, security effectiveness, reliabilty, needs, cost effectiveness, top management support, complexity, behavioral intention to use dan actual usage. Evaluasi goodness of fit dan resampling bootstraping digunakan untuk menganalisis kelayakan model. Evaluasi goodness of fit model struktural diukur menggunakan nilai predictive-relevance diperoleh nilai sebesar $=0,95$ yang artinya model memiliki nilai prediktif yang sangat baik. Hasil uji hipotesis diperoleh dengan menggunakan resampling bootstraping dengan menghitung hubungan antar variabel memiliki nilai thitung yang lebih besar $=2.01$ dalam adopsi cloud computing di rumah sakit Muhammadiyah, 8 (delapan) hipotesis diterima yaitu: Perceived usefulness, , Perceived ease of use, needs, top management support, complexity dan 3 (tiga) hipotesis ditolak yaitu: security, reliabilty dan cost effectivenes
\end{abstract}

Kata kunci: cloud computing, perceived usefulness, needs, top management support, behavioral intention to use, partial leastsquare (PLS).

\begin{abstract}
This article aims to determine the factors influencing the adoption of cloud computing in the hospital Muhammadiyah in Indonesia by using Technology Acceptance Model (TAM). The sample used in this study is 51 samples. The analytical tool used Partial Least Square (PLS) on SmartPLS program version 2.0. Factors supporting the adoption of cloud computing: perceived ease of use, perceived usefulness, security effectiveness, reliabilty, needs, cost effectiveness, top management support, complexity, behavioral intention to use and actual usage. Evaluation of the goodness of fit and bootstrapping resampling is used to analyze the feasibility of the model. Evaluation of the goodness of fit of the structural model is measured using predictive value-relevance obtained a value of $=0.95$, which means models have a very good predictive value. Hypothesis test results obtained using resampling bootstrapping to calculate the relationship between variables have the value t count bigger $=2.01$ in the adoption of cloud computing in the hospital Muhammadiyah, 8 (eight) hypothesis is accepted, namely: Perceived usefulness,, Perceived ease of use, needs, top management support, complexity, and 3 (three) hypothesis is rejected, namely: security, reliabilty and cost effectivenes
\end{abstract}

Keywords: cloud computing, perceived usefulness, needs, top management support, behavioral intention to use, partial leastsquare (PLS).

\section{PENDAHULUAN}

Cloud computing merupakan teknologi informasi yang saat ini mulai populer. Kedepannya akan semakin banyak pebisnis dan konsumen yang menggunakan layanan cloud computing, dan sebagian besar dari mereka akan memilih provider yang mampu mengakomodir kebutuhan end-to-end, dari perangkat hingga infrastruktur. Perubahan paradigma ini menyebabkan banyak organisasi yang bermigrasi dan mengadopsi teknologi cloud computing. Cloud computing merupakan fenomena baru, sehingga penelitian tentang topik ini masih terbatas, seperti penelitian mengenai cloud computing architecture [1], biaya dan keuntungan cloud computing [2], aplikasi potensial [3], faktor-faktor yang mempengaruhi adopsi cloud computing oleh perusahaan [4].

Salah satu fokus penelitian pengembangan di dunia adalah di bidang teknologi informasi kesehatan, salah satunya adalah awan kesehatan. Awan kesehatan adalah pelayanan kesehatan industri yang 
menyediakan teknologi informasi berbasis sistem cloud computing. Awan kesehatan mampu menghubungkan, memonitoring, mengendalikan untuk pengambilan keputusan dari setiap jaringan unit pelayanan kesehatan milik Muhammadiyah.

Menentukan dan membuat keputusan mengadopsi teknologi cloud computing untuk suatu organisasi bukanlah pekerjaan mudah dan sering kali berspekulasi tentang teknologi ini kedepannya apakah akan digunakan atau tidak, karena apabila tidak mempertimbangkan faktor-faktor apa saja yang mempengaruhi dalam mengadopsi cloud computing, akan memperbesar kesalahan dalam pengambilan keputusan.

TAM (Technology Acceptance Model) adalah salah satu model yang paling sering digunakan pada penelitian adopsi di bidang sistem informasi. Penelitian-penelitian yang ada memvalidasi kebenaran TAM dalam menguji berbagai macam penggunaan teknologi informasi pada berbagai jenis instansi dan perusahaan dan diakui oleh para peneliti di dunia.

Mendapatkan faktor-faktor yang mempengaruhi adopsi sebuah teknologi cloud computing bisa membantu para manager dan staf TI rumah sakit Muhammadiyah di Indonesia dalam mengevaluasi dan meningkatkan sistem TI di tempat mereka bekerja. Penelitian ini mencoba memberikan informasi yang sesuai bagi organisasi yang ingin membuat keputusan untuk mengadopsi cloud computing dan agar mereka tahu mana faktor-faktor yang penting bagi rumah sakit Muhammadiyah dalam mengadopsi cloud computing.

\section{KONSEP DASAR CLOUD COMPUTING}

Cloud computing bukanlah sebuah konsep baru, karena sebelumnya berasal dari teknologi komputasi terdistribusi berskala besar. Kemunculan cloud computing dilatarbelakangi oleh kebutuhan dunia industri dan komputerisasi akan pemanfaatan bersama sumber daya komputasi yang tersebar namun dapat digunakan sesuai dengan keinginan (on demand).

Cloud computing sebagai sebuah model yang memungkinkan adanya penggunaan sumber daya secara bersama-sama dan mudah, menyediakan jaringan akses di mana-mana, dapat dikonfigurasi, dan layanan yang digunakan sesuai keperluan.

\subsection{Technology Acceptance Model (TAM)}

Teori Technology Acceptance Model (TAM) adalah adaptasi dari Theory of Reasoned Action (TRA) yang dikembangkan oleh Davis [5] untuk konteks penerimaan (acceptance) pengguna terhadap Sistem Informasi. Tujuan dari pengembangan TAM ini adalah memberikan penjelasan terhadap faktorfaktor penentu penerimaan sistem informasi yang lebih umum sifatnya, sehingga dapat menjelaskan perilaku pengguna dari berbagai ragam teknologi komputasi dan pengguna. Sehingga dengan demikian dapat menjadi dasar untuk mengetahui dampak faktor eksternal (external variables) pada keyakinan (belief), sikap (attitude) dan niat (intentions) dalam penggunaan (actual usage) suatu sistem informasi.

\subsection{Cost Effectiveness}

Cost Effectiveness adalah hubungan antara biaya yang dikeluarkan dengan hasil yang menguntungkan [6]. Salah satu masalah penting dalam cloud computing adalah kemampuan untuk membayar layanan berdasarkan kebutuhan dan menghindari biaya yang besar untuk membeli sistem komputer [7] .

\subsection{Needs}

Beberapa perusahaan memerlukan teknologi cloud computing. Cloud computing memberikan berbagai macam layanan untuk kebutuhan akan sumber daya komputasi. Cloud computing juga bisa menjadi jalan keluar bagi yang mengalami keterbatasan sumber daya komputasi karena tingginya kebutuhan pengguna, dan memungkinkan pengguna untuk membayar berdasarkan kebutuhan. Hal yang paling menarik dalam cloud computing adalah memiliki ketersediaan, keterjangkauan, dan efisiensi yang tinggi dalam komputasi dalam mengatasi permintaan aplikasi yang tinggi. Cloud computing cocok sekali untuk organisasi besar seperti digunakan dalam pemerintahan, industri kesehatan atau jasa keuangan [8].

\subsection{Reliability}

Reliabilty berarti kualitasnya dapat dihandalkan dengan downtime yang minimum. Hal ini berguna bagi pengguna atau organisasi yang bergantung pada kehandalan komputasi, respon yang cepat, keamanan informasi dan penyimpanan data ke komputer yang bebasis aplikasi. Dengan software 
malware, pencegahan dan pengamanan data dapat mempengaruhi keandalan cloud computing. Karena alasan ini kehandalan software mempengaruhi kehandalan dari suatu cloud computing [6].

\subsection{Security Effectiveness}

Security effectiveness pada cloud computing dapat didefinisikan sebagai probabilitas subjektif dimana konsumen percaya bahwa informasi mereka tidak akan dilihat, disimpan, atau dimanipulasi ke pihak lain selama proses transmisi data dan disimpan secara konsisten [9]. Salah satu isu penting dari cloud computing adalah security effectiveness adalah faktor yang sangat penting untuk menerima layanan cloud.

\subsection{Top Management Support}

Top Management Support mengacu pada dukungan dari para pimpinan organisasi tentang sifat dan pemanfaatan teknologi cloud computing. Dukungan top management support sangat penting untuk menciptakan iklim yang kondusif dan menyediakan sumber daya yang memadai untuk adopsi teknologi baru [10].

\section{METODOLOGI PENELTIAN}

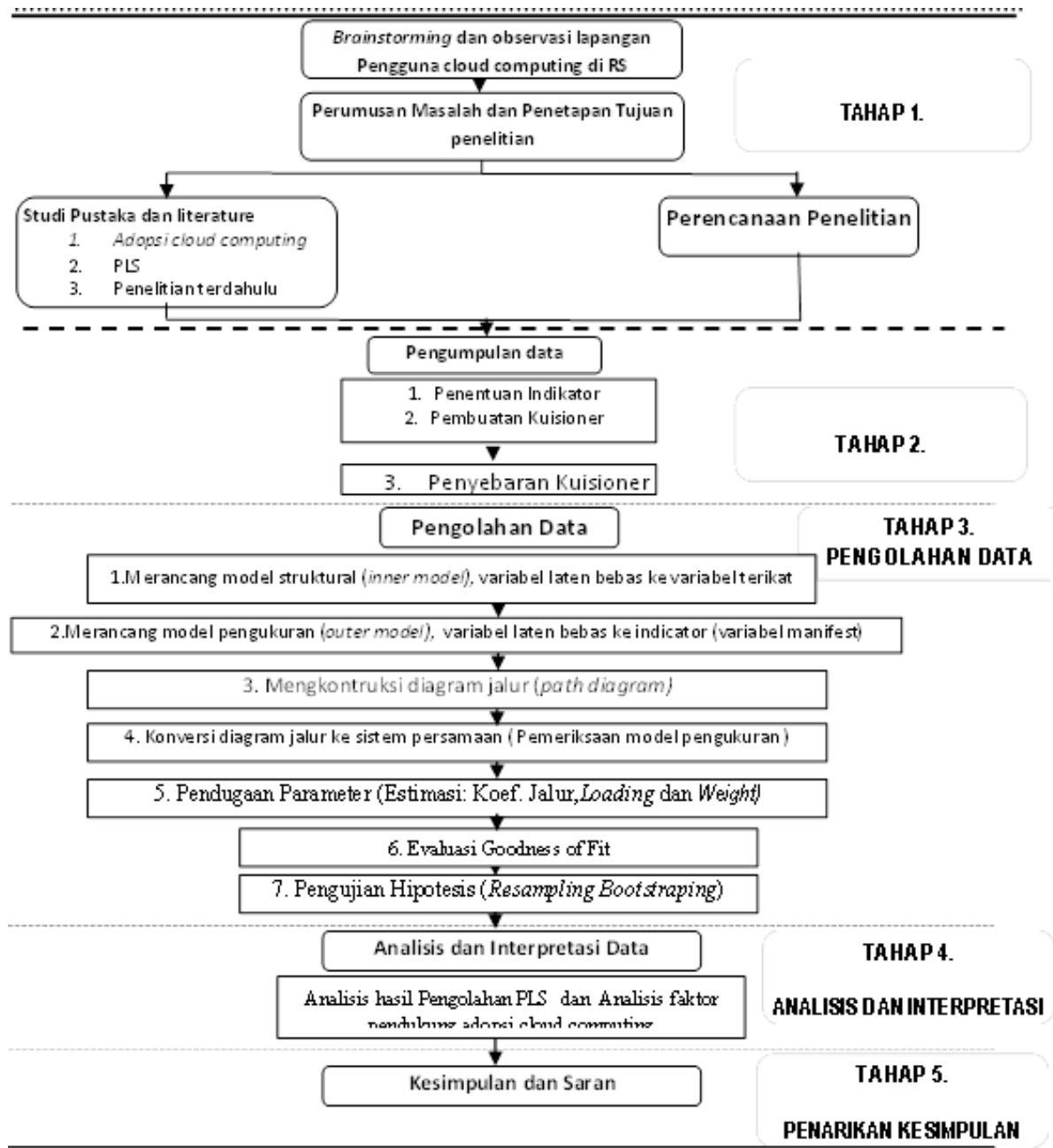

Gambar 1. Skema Alur Penelitian

\subsection{Langkah-langkah penelitian}

Perumusan masalah, proses identifikasi permasalahan diketahui setelah melalui proses pengamatan atas kondisi studi kasus yang dihadapi dan dikaitkan dengan pengembangan penelitian yang diperoleh 
melalui telaah pustaka. Studi pustaka dan literature terkait Usability, Partial Least Square (PLS) dan penelitian terdahulu yang memiliki kemiripan topik dengan penelitian ini. Perencanaan penelitian ini terdiri dari, tahap pengumpulan data, tahap pengolahan data, analisis dan interpretasi data dan penarikan kesimpulan dan saran sesuai pada gambar 1 .

Tahap pengumpulan data ini, meliputi empat hal, yaitu : penentuan indikator, pembuatan kuisioner, dan penyebaran kuisioner. Tahap pengolahan data menggunakan pengujian asumsi linieritas yang dimaksudkan untuk mengetahui linieritas hubungan antara variabel bebas dengan variabel terikat menggunakan teknik analisis metode Partial Least Square (PLS) dalam paket software SmartPLS versi 2.0. Tahapan analisis tersebut adalah: merancang model struktural (inner model), merancang model pengukuran (outer model), mengkonstruksi Diagram jalur (path Diagram), konversi diagram jalur ke dalam sistem persamaan, pendugaan parameter (estimasi: koef. jalur, loading dan weight), evaluasi goodness of fit, dan pengujian hipotesis (resampling bootstraping). Analisis hasil pengolahan PLS merupakan proses interpretasi data hasil SmartPLS dilengkapi dengan analisis langkah-langkah perbaikan mengacu pada hasil.

Penarikan kesimpulan berisikan kesimpulan penelitian atas permasalahan yang menjadi fokus pada pendahuluan, dengan mendasarkan pada diterima atau ditolaknya hipotesis. Bagian lain yang tidak kalah penting adalah implikasi teoritikal dan manajerial penelitian ini. Jadi, diharapkan ada kontribusi signifikan yang relevan dengan teori-teori sebelumnya dan kontribusi praktis bagi yang akan menggunakan hasil penelitian ini di tingkat pengambil keputusan. Bagian terakhir penyajian ini ditutup dengan keterbatasan dan agenda penelitian mendatang sebagai bentuk tanggung jawab ilmiah untuk pengembangan keilmuan di bidang yang dikaji.

\subsection{Model Penelitian}

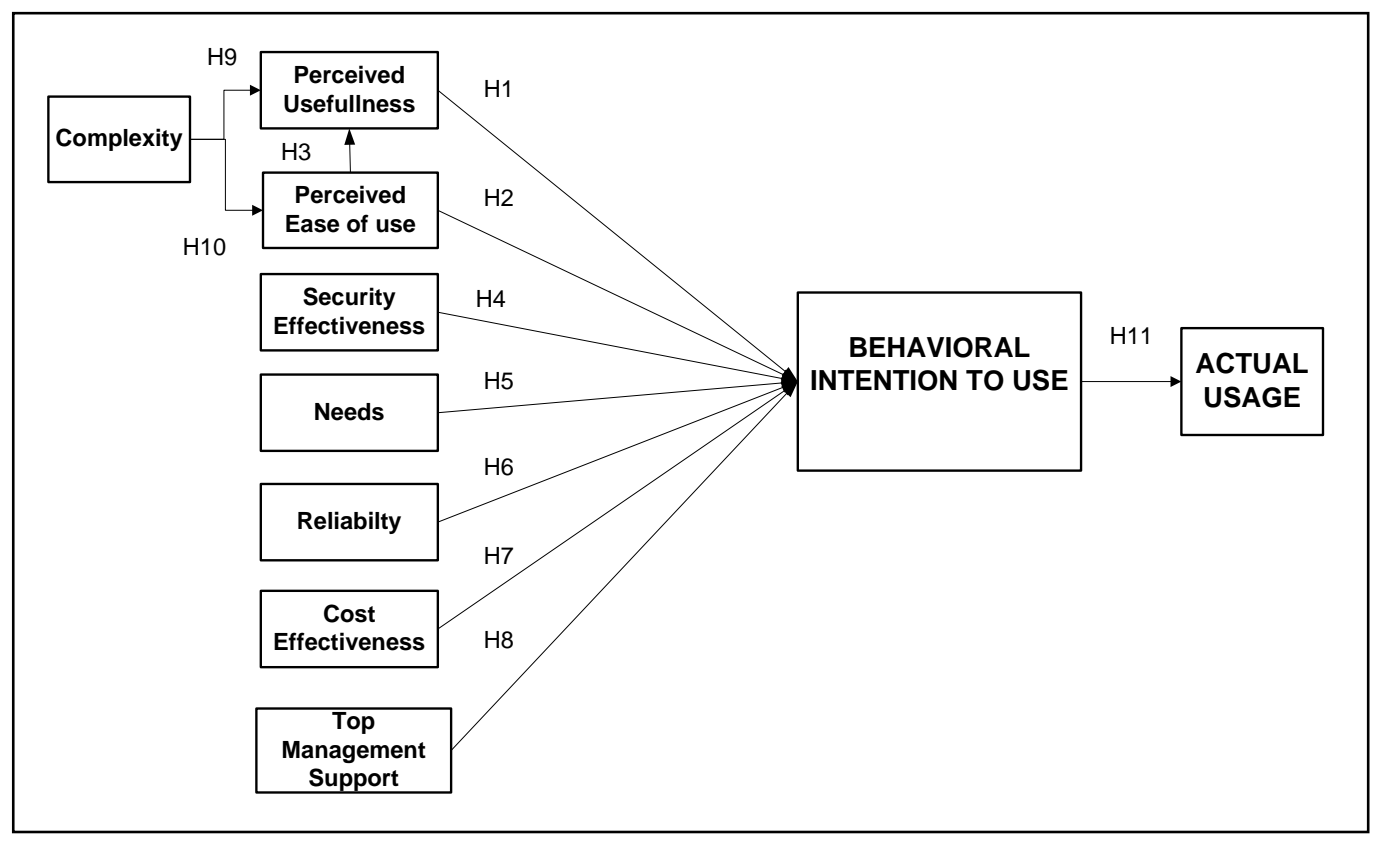

Gambar 2. Model Penelitian

Gambar 2 adalah model penelitian yang dikembangkan untuk menganalisis variabel yang mempengaruhi adopsi cloud computing di Rumah Sakit Muhammadiyah, penulis mengusulkan model penelitian TAM yang terintegrasi merujuk pada model yang dikembangkan oleh Davis [5] dan KwangKyu Seo [11]. Sedangkan cost effectiveness, security effectiveness, needs, reliability, top management support ditambahkan dan diidentifikasi dengan mempertimbangkan karakteristik dan pentingnya penggunaan layanan cloud computing.

\section{HASIL PENELITIAN}

\subsection{Uji validitas dan Reliabilitas Instrumen Penelitian}

Kriteria uji validitas dan reliabilitas instrumen pada penelitian ini seperti pada uraian berikut: 


\subsubsection{Convergent Validity}

Tabel 1. Outer Loading setiap indikator

\begin{tabular}{|c|c|c|}
\hline Indikator & Original Sample $(O)$ & T Statistics $(|\mathrm{O} / \mathrm{STERR}|)$ \\
\hline AU1 <- Actual Usage & 0.852514 & 26.488575 \\
\hline AU2 <- Actual Usage & 0.666545 & 7.734350 \\
\hline AU3 $<-$ Actual Usage & 0.664322 & 9.348563 \\
\hline AU4 $<-$ Actual Usage & 0.809292 & 26.490466 \\
\hline AU5 <- Actual Usage & 0.838149 & 18.604854 \\
\hline BII <- Behavioral Intention to Use & 0.867842 & 38.270108 \\
\hline BI2 <- Behavioral Intention to Use & 0.890285 & 51.107975 \\
\hline BI3 <- Behavioral Intention to Use & 0.888219 & 43.086289 \\
\hline CE1 <- Cost Effectiveness & 0.755958 & 5.935273 \\
\hline CE2 <- Cost Effectiveness & 0.885325 & 18.868133 \\
\hline CE3 <- Cost Effectiveness & 0.820953 & 10.236266 \\
\hline CE4 <- Cost Effectiveness & 0.849889 & 15.380592 \\
\hline CO1 <- Complexity & 0.967109 & 89.539947 \\
\hline CO2 <- Complexity & 0.973977 & 169.313567 \\
\hline$N E 1<-$ Needs & 0.908005 & 47.494885 \\
\hline$N E 2<-$ Needs & 0.911427 & 58.878500 \\
\hline NE3 $<-$ Needs & 0.928060 & 56.792351 \\
\hline PE1 <-Perceived ease of use & 0.897717 & 66.409513 \\
\hline PE2 <-Perceived ease of use & 0.883039 & 45.394641 \\
\hline PE3 <- Perceived ease of use & 0.790287 & 20.989010 \\
\hline PE4 <-Perceived ease of use & 0.745981 & 14.252422 \\
\hline PU1 <- Perceived Usefullness & 0.939863 & 59.737790 \\
\hline PU2 <-Perceived Usefullness & 0.919105 & 48.694716 \\
\hline PU3 <- Perceived Usefullness & 0.837472 & 28.284620 \\
\hline PU4 <- Perceived Usefullness & 0.895275 & 48.223454 \\
\hline RE1 <- Reliability & 0.852358 & 14.666149 \\
\hline RE2 <- Reliability & 0.873646 & 15.028861 \\
\hline RE3 <- Reliability & 0.909944 & 8.361211 \\
\hline SE1 <- Security Effectiveness & 0.925753 & 60.144661 \\
\hline SE2 <- Security Effectiveness & 0.888652 & 31.489327 \\
\hline SE3 <- Security Effectiveness & 0.699470 & 9.131747 \\
\hline TM1 <- Top Management Support & 0.843020 & 32.596746 \\
\hline TM2 <- Top Management Support & 0.934309 & 65.315472 \\
\hline TM3 <- Top Management Support & 0.846833 & 24.461186 \\
\hline TM4 <- Top Management Support & 0.888631 & 39.394053 \\
\hline
\end{tabular}

Semua indikator yang digunakan pada penelitian ini memiliki loading factor lebih besar dari 0,5 dan signifikan ( $\mathrm{t}$ hitung $>\mathrm{t}$ tabel), sehingga tidak ada indikator yang dibuang. $\mathrm{t}$ tabel $=2.01$ dapat dilihat di Tabel 1. 


\subsubsection{Discriminant Validity}

Nilai akar kuadrat dari AVE setiap konstruk harus lebih besar daripada korelasi antara konstruk dengan konstruk lainnya dalam model. Selain itu nilai AVE masing-masing konstruk harus lebih besar dari 0,5 sehingga dapat kita simpulkan bahwa model memiliki discriminant validity yang cukup dapat dilihat di Tabel 2.

Tabel 2. AVE dan akar AVE

\begin{tabular}{cc}
\hline Variabel Laten & $\boldsymbol{R}$ Square \\
\hline Actual Usage & 0.472138 \\
Behavioral Intention to Use & 0.825775 \\
Perceived Usefullness & 0.514731 \\
Perceived ease of use & 0.131198 \\
\hline
\end{tabular}

\subsubsection{Composite Reliabilty}

Semua variabel yang digunakan pada penelitian ini memiliki composite reliability dan Cronbachs Alpha lebih besar dari 0,7. hal ini menunjukkan bahwa semua variabel pada penelitian ini memiliki reliabilitas yang baik, dapat dilihat pada Tabel 3.

Tabel 3. Composite reliability

\begin{tabular}{ccc}
\hline Variabel & Composite Reliability & Cronbachs Alpha \\
\hline Actual Usage & 0.878472 & 0.829247 \\
Behavioral Intention to Use & 0.913241 & 0.857473 \\
Complexity & 0.970115 & 0.938593 \\
Cost Effectiveness & 0.897824 & 0.855795 \\
Needs & 0.939801 & 0.904097 \\
Perceived Usefullness & 0.943741 & 0.920003 \\
Perceived ease of use & 0.899207 & 0.849668 \\
Reliability & 0.910591 & 0.853604 \\
Security Effectiveness & 0.879723 & 0.799288 \\
Top Management Support & 0.931348 & 0.901211 \\
\hline
\end{tabular}

\subsection{Pemeriksaan Googness Of Fit Model}

Pengujian atau penilaian terhadap model struktural dilakukan dengan melihat nilai R-square untuk konstruk dependen, dan uji t serta signifikansi dari koefisien parameter jalur strukturalnya yang didapat lewat prosedur bootsraping.

Tabel 4. R-Square

\begin{tabular}{cc}
\hline Variabel Laten & $\boldsymbol{R}$ Square \\
\hline Actual Usage & 0.472138 \\
Behavioral Intention to Use & 0.825775 \\
Perceived Usefullness & 0.514731 \\
Perceived ease of use & 0.131198 \\
\hline
\end{tabular}

Berdasarkan Tabel 4, dihitung berdasarkan nilai $\mathrm{R}^{2}$ masing-masing variabel endogen, yaitu: 1) variabel actual usage (AU) diperoleh $\mathrm{R}^{2}$ sebesar $0.47 ; 2$ ) variabel behavioral intention (BI) diperoleh $\mathrm{R}^{2}$ sebesar 0.83 ; 3) variabel perceived usefulness (PU) diperoleh $\mathrm{R}^{2}$ sebesar 0.51 ; dan 4) variabel perceived ease of use (PE) ) diperoleh $\mathrm{R}^{2}$ sebesar 0.13 .

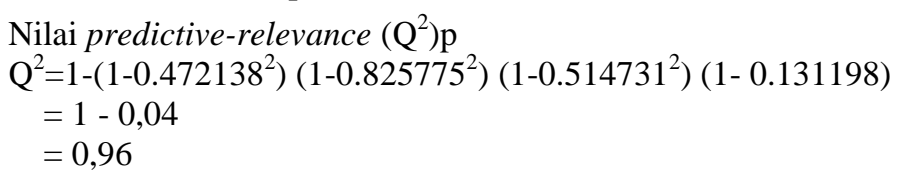

Nilai predictive-relevance sebesar $\mathrm{Q}^{2}=0,95949$ atau 95,94\% dengan rumus $\mathrm{Q}^{2}=1-\left(1-\mathrm{R}_{1}{ }^{2}\right)\left(1-\mathrm{R}_{2}{ }^{2}\right) \ldots$ $\left(1-\mathrm{R}_{\mathrm{p}}{ }^{2}\right)$. Artinya model dapat menjelaskan fenomena adopsi cloud computing dikaitkan dengan beberapa variabel sebesar 95,94\%. Oleh karena itu model dapat dikatakan sangat baik, atau model memiliki nilai prediktif yang sangat baik. Pada akhirnya model dapat digunakan untuk pengujian hipotesis. 


\subsection{Pengujian Hipotesis}

Pengujian hipotesis dilakukan dengan menggunakan metode resampling Bootstrap yang dikembangkan oleh Geisser \& Stone. Statistik uji yang digunakan adalah uji t. Apabila t hitung yang diperoleh untuk masing-masing hubungan variabel memiliki nilai t hitung yang lebih besar dibandingkan dengan t tabel sebesar 2.01 maka hubungan itu signifikan

A. Berdasarkan hasil analisis pada Gambar 3, menunjukkan bahwa koefisien jalur pengaruh langsung perceived usefullness terhadap behavioral intention to use diperoleh nilai 0.178 pada t-statistic 2.03. Koefisien bertanda positif dapat diartikan bahwa hubungan antara perceived usefullness dan behavioral intention to use adalah searah, nilai t-statistik 2.03 lebih dari nilai t-tabel yaitu 2,01 maka hubungan antar variabel signifikan.

B. Berdasarkan hasil analisis pada Gambar 3 menunjukkan bahwa koefisien jalur pengaruh langsung perceived ease of use terhadap behavioral intention to use diperoleh nilai 0,258 pada t-statistic 2,806 . Koefisien bertanda positif dapat diartikan bahwa hubungan antara perceived ease of use dan behavioral intention to use adalah searah, nilai t-statistik 2,806 lebih dari nilai t-tabel yaitu 2,01 maka hubungan antar variabel signifikan.

C. Berdasarkan hasil analisis pada Gambar 3 menunjukkan bahwa koefisien jalur pengaruh langsung perceived ease of use terhadap perceived usefullness diperoleh nilai 0,588 pada t-statistic 5,550. Nilai t-statistik 5550 lebih dari nilai t-tabel yaitu 2,01 maka hubungan antar variabel signifikan

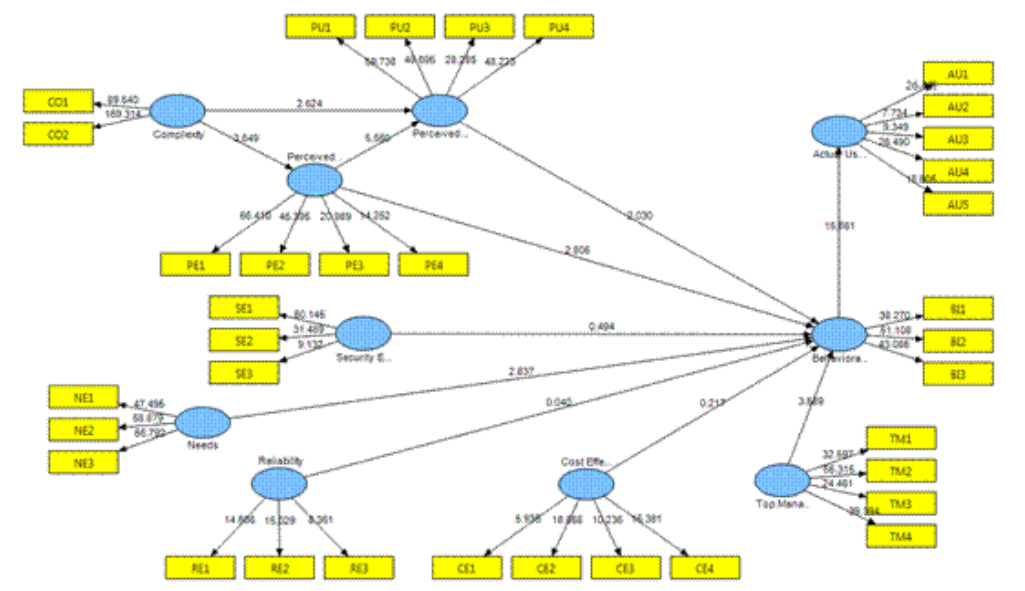

Gambar 3. Hasil Pengujian Uji t

D. Berdasarkan hasil analisis pada Gambar 3 menunjukkan bahwa koefisien jalur pengaruh langsung security effectiveness terhadap behavioral intention to use diperoleh nilai 0,0290 pada t-statistic 0,493. Koefisien bertanda positif dapat diartikan bahwa hubungan antara perceived ease of use dan perceived usefullness adalah searah, nilai t-statistik 0,493 kurang dari nilai t-tabel yaitu 2,01 maka hubungan antar variabel tidak signifikan.

E. Berdasarkan hasil analisis pada Gambar 3 menunjukkan bahwa koefisien jalur pengaruh langsung needs terhadap behavioral intention to use diperoleh nilai 0,274 pada t-statistic 2,836. Koefisien bertanda positif dapat diartikan bahwa hubungan antara needs dan behavioral intention to use adalah searah, nilai t-statistik 2.836 lebih dari nilai t-tabel yaitu 2,01 maka hubungan antar variabel signifikan.

F. Berdasarkan hasil analisis pada Gambar 3 menunjukkan bahwa koefisien jalur pengaruh langsung reliabilty terhadap behavioral intention to use diperoleh nilai 0,002 pada t-statistic 0,039. Koefisien bertanda positif dan t-statitstik kurang dari 2,01 yang artinya tidak signifikan.

G. Berdasarkan hasil analisis pada Gambar 3 menunjukkan bahwa koefisien jalur pengaruh langsung cost effectiveness terhadap behavioral intention to use diperoleh nilai 0,01 pada t-statistic 0,217. Koefisien bertanda positif dan t-statitstik kurang dari 2,01 yang artinya tidak signifikan.

H. Berdasarkan hasil analisis pada Gambar 3 menunjukkan bahwa koefisien jalur pengaruh langsung top management support terhadap behavioral intention to use diperoleh nilai 0,282 pada t-statistic 3,588. Koefisien bertanda positif dapat diartikan bahwa hubungan antara reliabilty dan behavioral intention to use adalah searah, nilai t-statistik lebih dari 3,588 maka hubungan antar variabel signifikan

I. Berdasarkan hasil analisis pada Gambar 3 menunjukkan bahwa koefisien jalur pengaruh langsung complexity terhadap perceived usefullness diperoleh nilai 0,248 pada t-statistic 2,624. Koefisien bertanda positif dan nilai statistik lebih dari t-tabel 2.01 dapat diartikan signifikan. 
J. Berdasarkan hasil analisis pada Gambar 3 menunjukkan bahwa koefisien jalur pengaruh langsung complexity terhadap perceived ease of use diperoleh nilai 0,362 pada t-statistic 3,648. Koefisien bertanda positif dan nilai t-statistik lebih dari nila t-tabel 2,01. artinya hasil penelitian ini menunjukkan bahwa complexity (kerumitan) suatu teknologi cloud computing mempengaruhi perceived ease of use teknologi cloud computing.

K. Berdasarkan hasil analisis pada Gambar 3 menunjukkan bahwa koefisien jalur pengaruh langsung behavioral intention to use terhadap actual usage diperoleh nilai 0,687 pada t-statistic 16,86 . Koefisien bertanda positif dan nilai t-statistik lebih dari t-tabel 2,01 maka hubungan antar variabel signifikan

\section{KESIMPULAN}

Berdasarkan hasil analisis fakator-faktor yang mempengaruhi adopsi cloud commputing di rumah sakit Muhammadiyah, diperoleh kesimpulan bahwa sebelas hipotesis yang diuji, terdapat delapan yang positif signifikan dan hanya tiga yang positif dan tidak siginifikan:

1) Variabel behaviora intention to use berpengaruh secara positif dan signifikan terhadap actual usage. Variabel perceived usefullness berpengaruh secara positif dan siginifikan terhadap behavioral intention to use. Variabel perceived ease of use berpengaruh secara positif dan signifikan terhadap behavioral intention to use. Variabel needs berpengaruh secara positif dan signifikan terhadap behavioral intention to use. Variabel top management support berpengaruh secara positif dan signifikan terhadap behavioral intention to use. Varaibel perceived ease of use berpengaruh secara positif dan signifikan terhadap perceived usefullness. Variabel complexity berpengaruh secara positif dan signifikan terhadap perceived usefullness dan perceived ease of use.

2) Variabel cost effectiveness berpengaruh secara positif dan tidak signifikan terhadap behavioral intention to use. Variabel security effectiveness secara positif dan tidak signifikan terhadap behavioral intenttion to use. Variabel reliability berpengaruh secara positif dan tidak sigifikan terhadap behavioral intention to use.

\section{DAFTAR PUSTAKA}

[1] Rochwerger, B., et al.. 2009. "The Reservoir Model and Architecture for Open Federated Cloud Computing". IBM J. Research and Development 53, 4.

[2] Assuncao, M., D., Costanzo, A., \& Buyya, R., (2009), "Evaluating the cost benefit of using Cloud computing to extend the capacity of cluster. In Proceeding of the 18th ACM International Symposium on High Performance Distributed Computing, New York, NY; ACM, 53(4).

[3] Liu, H., and Orban, D. (2008) Gridbatch: Cloud computing for large-scale data-intensive batch applications, Cluster Computing and the Grid, 2008. CCGRID'08. 8th IEEE International Symposium on (pp. 295-305).

[4] Wu, W. (2011). Developing an explorating model for SaaS adoption. Expert System with Application, 38, 15057-15064. doi:10.106/j.eswa.2011.05.039.

[5] Vankatesh, V., \& Davis, F. D. (1996). A Model of The Antencendents of Perceived ease of Use; Development and Tes Decision, Sciences , 27(3), 451-481.

[6] Rahimli, A. (2013). Factor Infulencing Organization Adoption Decisision of Cloud Computing. International Journal of Cloud Computing and Services Science.

[7] Amburst, M., Fox, A., \& Griiftih, R. (2009). Above the clouds: A Berkeley View Of Cloud Computing Technical Report. University of California at Barkeley.

[8] Biddick, M. (2008). A Walk in the Clouds. Information Week Analytics Reports. Manhassett, NY: United Bussines Media Limited.

[9] I. Lule, T. O., \& Waema, T. M. (2013). International Journal of Computing and ICT Research. Vol. 6 no.3.

[10] Wu, W. (2011). Developing an explorating model for SaaS adoption. Expert System with Application, 38, 15057-15064. doi:10.106/j.eswa.2011.05.039.

[11] Seo, K.-K. (2013). An Explorative Model For B2B Cloud Services Adoption in Korea - Focusing on IaaS Adoption. International Journal of Smart Home. 